\title{
EDITORIAL
}

\section{Workshop on Minimal Residual Disease}

9th Expert Meeting for Pediatric Oncology and Hematology, funded by the Kind-Philipp Foundation, Germany

Reisensburg/Ulm, 24-26 October 1999

In October 1998, the Kind-Philipp Foundation asked Martin Schrappe (Hannover) and Claus R Bartram (Heidelberg) to set up an organizing committee to invite a faculty of experts for a special workshop on minimal residual disease (MRD) in malignant disease. The intention of this workshop was not only to bring scientists together from different backgrounds, but to have them teach a small group of young researchers and to foster scientific discussion and exchange. The organizing committee (M Schrappe, CR Bartram, JJM van Dongen, M Kneba, G Henze) assembled an international faculty of 30 basic scientists and clinical researchers from 10 different countries and similarly sized group of young fellows, mainly from Germany, Austria and Italy.

Initially, the workshop covered the issues of leukemia etiology (fetal origin, deletion of parental genes as potential risk), the detection of leukemia at birth (Guthrie cards), and the impact of gene rearrangements of 11q23 in childhood ALL. Subsequent speakers coming from research in solid tumors (neuroblastoma, breast cancer) focused on new technologies of detecting minimal amounts of disseminated tumors cells or tumor cell DNA, thus raising important questions about how to define clinical stages of malignant disease at diagnosis as much as during follow-up. The second day was devoted to new technological aspects for the detection of minimal residual disease in leukemia and disseminated cancer. Most important were the issues of quantification, in particular due to the introduction of new more automated technology (LightCycler, Taqman). This discussion raised the question of whether results generated by different techniques are comparable. In particular for the leukemias, the comparison of RTPCR for fusion genes, clonospecific PCR for immunoglobulin and T cell receptor (TCR) genes, and immunophenotyping for leukemia-specific antigen detection were debated.

The third major part of the workshop illustrated the important results of the clinical application of MRD detection in various clinical settings and in different biological subtypes. New data were presented with regard to the prognostic impact of MRD in adult and pediatric leukemia protocols (including stem cell transplantation), as well as in the treatment of nonHodgkin's lymphoma and Ewing's sarcoma. Some of the new data indicate that not only the level of MRD at a certain point in treatment, but also the type and intensity of treatment before material for MRD detection is obtained, is important for its interpretation. This implies that (semiquantitative) MRD results have not only to be taken with caution with regard to the detection technique, but also with respect to treatment applied. The final session focused on some fundamental issues arising from the arrival of the new detection techniques in the clinical setting. First of all, the prognostic impact of MRD needs to be evaluated in prospective clinical trials whenever such technology is being introduced into the treatment of a new disease entity, and with predefined conditions for quality control of the method. The high sensitivity available today requires new definitions for 'response', 'remission', and 'relapse' which up to this point are based on morphology in cytology and histopathology, or on imaging techniques in the management of solid tumors and their metastases. Most participants agreed that an uncontrolled introduction of new definitions for remission and relapse would be detrimental for clinical trials. Also, the introduction of this kind of detection technology would not necessarily help the patient, as the clinical behavior of minimal disease is not known for various tumor entities. With regard to cost/benefit aspects it is mandatory to prove first in well-designed clinical trials that any new stratification of treatment according to new MRD detection technique will benefit the patients.

This issue of Leukemia comprises several contributions of this workshop published as Synopses and chosen by the organizing committee. The coordinator wishes to thank the Kind-Philipp Foundation, Essen, Germany, for its generous support, the members of the organizing committee for their input, and the participants for their contributions. 


\title{
Workshop on Minimal Residual Disease: Scientific Program
}

\section{Session I}

Opening remarks

P Beck, Kind-Philipp Foundation, Essen

G Henze, Chairman, Society of Pediatric Hematology

and Oncology $(\mathrm{GPOH})$, and Member of the Board, Kind-Philipp Foundation

Origin of malignant systemic disease (1)

Chair: CR Bartram, P Ambros

Fetal origins of childhood leukemia

Deletion of parental GST genes as possible susceptibility factor in the etiology of infant leukemia

The promiscuity of $11 \mathrm{q} 23 / \mathrm{MLL}$ - the story goes on

Rapid isolation of chromosomal breakpoints from patients with $t(4 ; 11)$ ALL: implications for basic and clinical research

Detection of leukemia specific antigen receptor gene rearrangements in Guthrie cards

Distribution of malignant disease (2)

Chair: M Greaves, A Biondi

Minimal detectable disease in patients with solid tumors: diagnosis and surveillance

Biological characteristics of diesseminated carcinoma cells in bone marrow and lymph nodes

Detection of circulating tumor DNA in the blood (plasma/serum) of cancer patients

A lesson from MRD in leukemia

M Greaves

A Biondi

A Borkhardt

R Marschalek

K Fasching

P Ambros

K Pantel

P Anker

L Foroni

\section{Session II}

Detection of minimal malignant disease: technological aspects (1)

Sensitivity/time effort/limitations

Chair: JJM van Dongen, AA Morley

Flow cytometry for immunphenotypic detection of MRD

$\mathrm{Ig} / \mathrm{TCR}$ gene rearrangements - PCR

Chromosomal aberrations/Fusion genes

Single cells $(\mathrm{CGH})$

Strategies to overcome the limitations in MRD detection

D Campana

R Panzer-Grümayer

J Harbott

M Speicher

P Ambros

Detection of minimal malignant disease: technological aspects (2)

Quantification

Chair: D Campana, EA Macintyre

The use of monoclonality and sensitive quantification for study of MRD in acute leukemia

Light cycler technology using IgH and Ig markers

Strategies for quantification of MRD

Quantification of leukemia-specific immunophenotypes and prospective utilization in childhood ALL

CML: Surveillance of bcr/abl positive progenitor cells

\author{
AA Morley \\ T Flohr \\ JJM van Dongen \\ D Campana \\ A Hochhaus
}

\section{Session III}

Clinical implications of MRD detection (1) in leukemia and sarcoma

Experience from clinical studies

Chair: H Riehm, K Pantel

Differences in MRD-kinetics between T-ALL and precursor-B cell leukemia

Early response in ALL: MRD vs morphology

$M R D$ in $A P L$

MRD in Ewing sarcoma

Multiparameter flow cytometry for detection of ALL in trial ALL-BFM 95

Clinical significance of MRD monitoring in TEL/AML1-positive ALL patients

Results from the NOPHO ALL trials: impact of MRD

$M$ Willemse

R Panzer-Grümayer

A Biondi

A Zoubek

MN Dworzak

J Trka

K Schmiegelow 
Outcome prediction by MRD at end of induction depends on therapeutic regimen MRD detection in the cooperative Ewing trials

Clinical implications of MRD detection (2)

Rational prospective application of MRD in clinical studies

Chair: G Henze, M Kneba

Clinical applications of MRD in adult ALL

Adult NHL: significance of MRD

Pediatric ALL: stratification and endpoints

TEL/AML1 in relapsed ALL

Clinical implications of MRD detection (3)

BMT and prognostic impact of leukemia surveillance

Chair: A Reiter, T Klingebiel

Approaches for MRD detection after allogeneic BMT

Residual leukemia and outcome of BMT

MRD in ALL patients prior to allogeneic SCT

Special lecture: Etiology of acute leukemia

\section{Session IV}

Minimal requirements for adequate use of MRD techniques (1)

Chair: L Foroni, T Lion

Open discussion

Future perspectives (2)

Chair: M Schrappe, C Steward

New definitions required for 'diagnosis', 'response', and 'relapse' based on new detection techniques of minimal disease?

MRD monitoring: quality control

Cost/benefit analysis:

Impact on cure?

Application in countries with limited resources

Open discussion
U z Stadt

KL Schäfer

EA Macintyre

M Kneba

M Schrappe

K Seeger

T Lion

C Steward/N Goulden

$\mathrm{P}$ Bader/T Klingebiel

M Greaves
A Biondi
A Morley
D Campana
M Kneba
JJM v Dongen

CR Bartram

L Foroni

P Anker

JJM van Dongen

EA Macintyre

J Harbott

H Riehm 